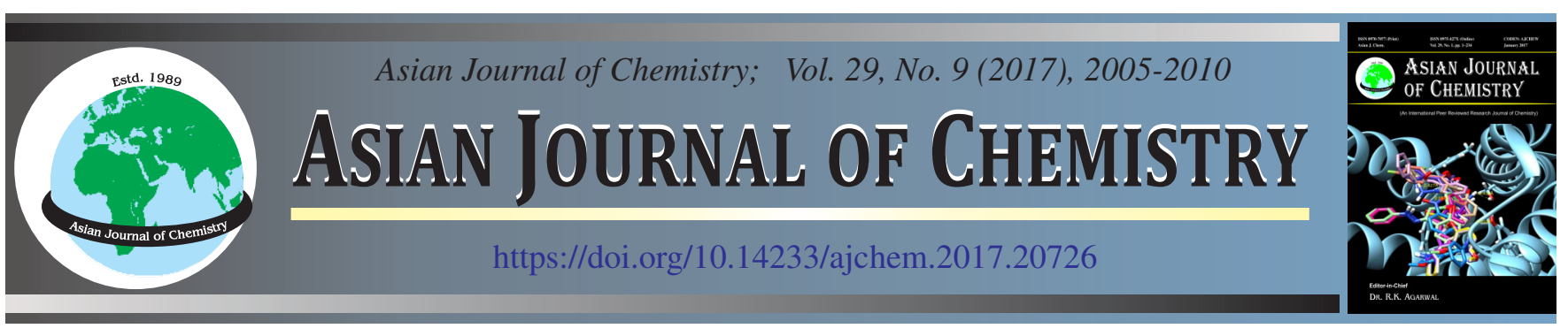

\title{
X-Ray Analysis of Cadmium Oxide Nanostructured Films Synthesized with Different Precursor Molarities by Silar Method
}

\author{
Hiten Sarma ${ }^{1, *}$, Dhruba Chakrabortty ${ }^{2}$ and K.C. Sarma ${ }^{1}$
}

${ }^{1}$ Department of Instrumentation \& USIC, Gauhati University, Guwahati-781 014, India

${ }^{2}$ Department of Chemistry, B.N. College, Dhubri-783 324, India

*Corresponding author: E-mail: hitensarma7@gmail.com; ritul1967@ rediffmail.com

Received: 24 April 2017;

Accepted: 29 May 2017;

Published online: 15 July 2017;

AJC-18484

Nanostructured cadmium oxide thin films have been synthesized onto suitably cleaned glass substrates by SILAR (successive ionic layer
adsorption and reaction) method. X-ray diffraction study confirms the formation of nanocrystalline cubic phase of cadmium oxide in the
films. Lattice constant is determined using Nelson Riley plots. Using X-ray broadening, crystallite sizes, lattice strain, stress and energy
density were studied by using Williamson-Hall method and modified Williamson-Hall method. From literature review, it is seen that a
number of researchers have applied these two methods for structural characterization of thin films of different nanocrystals, but till now
modified Williamson-Hall method has not been used for CdO nanocrystals. Hence, we have used these methods for structural characterization
of deposited CdO thin films. The ultra-high resolution transmission electron microscopic (UHRTEM) study shows that the shape of the
particles is nearly spherical and the average particle size agrees well with the result obtained from X-ray diffraction study. Selected area
electron diffraction patterns have also supported the formation of cubic phase of cadmium oxide.
Keywords: Cadmium oxide thin films, Williamson-Hall plot, Nelson-Riley plot, Size-strain plot.

\section{INTRODUCTION}

Nanostructured materials have drawn attentions to the researchers due to the unique physical and chemical properties of nanomaterials, which are different from those of either the bulk materials or single atoms [1]. The reduction of the size of materials causes a deviation of their physical and chemical properties from the bulk and such resultant materials (nanoparticles) are known to possess potential applications and novel properties [2]. Among the different metal oxide films, $\mathrm{CdO}$ is an important n-type semiconductor with a cubic structure, which belongs to the II-VI group, with a direct band gap of $2.5 \mathrm{eV}$ and indirect band gap $1.98 \mathrm{eV}$ [3]. Up to now, various methods have been employed to prepare the cadmium oxide nanostructures such as hydrothermal method [4], microwave-assisted combustion method [5], solvothermal method [6], chemical coprecipitation method [7], vapour phase transport [8], thermal evaporation [9], sonochemical method [10] and mechano chemical method [11]. We have used SILAR (successive ionic layer adsorption and reaction) technique for the preparation of thin films which is presently attracting considerable attention, as it does not require sophisticated instrumentation like vacuum system and other expensive equipment. Simple equipment like hot plate with magnetic stirrer is needed for this method [12].
Nelson Riley plot has been used by many research groups for calculating the lattice constant of a cubic system $[13,14]$. We have also used it for the same purpose. Crystallite size, lattice strain and stress have been calculated using WilliamsonHall method, modified Williamson-Hall method and uniform deformation energy density model [15-17]. Size-strain plot (SSP) have also been used for finding size and strain of the prepared films [14,18,19], which is also used here. As far our best of knowledge modified Williamson-Hall method for structural characterization is used mainly for $\mathrm{CdS}, \mathrm{PbS}, \mathrm{ZnO}$, etc. nanostructures and detailed application of modified WilliamsonHall method for $\mathrm{CdO}$ nanostrucured is not shown yet. Hence we have used application of modified Williamson-Hall method for structural characterization of synthesized $\mathrm{CdO}$ films.

\section{EXPERIMENTAL}

Cleaning of the substrate: The microscope glass substrate was cleaned with following steps (1) washed with mild detergent, (2) rinsed with distilled water, (3) dipped in dilute chromic acid for $3 \mathrm{~h}$ (4) rinsed thoroughly with distilled water and (5) heated at $20^{\circ} \mathrm{C}$ for $10 \mathrm{~min}$ by keeping the substrate vertically.

Cadmium nitrate hexahydrate, sodium hydroxide were purchased from Merck and were used as received since they 
were of analytical reagent grade with $99 \%$ purity. Double distilled water was used for all procedures of sample preparation and dilution.

Deposition of thin film: Cadmium oxide thin films were deposited onto the cleaned glass substrates by alternate immersion of the glass substrate in $\mathrm{Cd}\left(\mathrm{NO}_{3}\right)_{2}\left(\mathrm{Cd}^{2+}\right.$ ion source $)$ and in double distilled water $\left(\mathrm{OH}^{-}\right.$source $)$at room temperature. Cadmium nitrate and $\mathrm{H}_{2} \mathrm{O}$ served as the cationic and anionic solutions respectively. The alkalinity of cadmium nitrate solution was increased to $\mathrm{pH} \sim 12$ with the addition of sodium hydroxide. As the cleaned glass substrate was immersed in the alkaline cadmium nitrate solution, cadmium complex adsorbed on the substrate. The glass substrate with the cadmium complex is then immersed in distilled water and the reaction occurred on the glass surface to form $\mathrm{Cd}(\mathrm{OH})_{2}$. The period of dipping the substrate in the cadmium bath (30 s) was referred as "adsorption" and that in $\mathrm{H}_{2} \mathrm{O}(15 \mathrm{~s})$ as "reaction". This process forms one cycle and was repeated 50 times in order to increase the film thickness. After each cycle, the glass slide was rinsed with distilled water and after a complete cycle the films were dried with an air dryer. Finally, the deposited films were annealed in air at $350{ }^{\circ} \mathrm{C}$ for $2 \mathrm{~h}$ to transform the hydroxide phase to the oxide. The precursor solutions were prepared by adding $\mathrm{Cd}\left(\mathrm{NO}_{3}\right)_{2}$ solutions of $0.25,0.50$ and 0.75 molar concentrations separately to an aqueous solution of $2 \mathrm{M} \mathrm{NaOH}$ under a high stirring rate $(200 \mathrm{rpm})$ condition. During the stirring process a constant temperature $30{ }^{\circ} \mathrm{C}$ was maintained for $3 \mathrm{~h}$.

Mechanism of thin film formation: Dipping the glass slides in the beaker containing cadmium nitrate and excess sodium hydroxide solution causes a cadmium complex ion to adsorb on the substrate due to attractive forces between ions in the solution and that on the glass. Atoms or molecules of glass surface possess unbalanced or residual force and hold the substrate particles. The cadmium complex ions can be represented with the following equations:

$$
\begin{gathered}
\mathrm{Cd}\left(\mathrm{NO}_{3}\right)_{2}+2 \mathrm{NaOH} \longrightarrow \mathrm{Cd}(\mathrm{OH})_{2}+2 \mathrm{NaNO}_{3} \\
\mathrm{Cd}(\mathrm{OH})_{2}+\mathrm{NaOH} \longrightarrow \mathrm{Na}(\mathrm{Cd})(\mathrm{O})^{2-}+\mathrm{H}_{2} \mathrm{O}+2 \mathrm{H}^{+}
\end{gathered}
$$

The glass substrate with the adsorbed cadmium sodium oxide ion is immersed into a beaker of distilled water and the ion is converted into cadmium hydroxide. Sodium ion in the complex is attracted to the hydroxide ion to form sodium hydroxide while the $\mathrm{CdO}^{2-}$ in the complex is attracted to the $\mathrm{H}^{+}$to form the cadmium hydroxide ion.

$$
\begin{gathered}
(\mathrm{Na}) \mathrm{CdO}^{2-}+\mathrm{H}_{2} \mathrm{O} \longrightarrow \mathrm{Cd}(\mathrm{OH})^{2-}+\mathrm{NaOH} \\
\mathrm{Cd}(\mathrm{OH})^{2-}+\text { heat } \longrightarrow \mathrm{CdO}+\mathrm{H}_{2} \mathrm{O}
\end{gathered}
$$

On annealing at a temperature of $350{ }^{\circ} \mathrm{C}$ the cadmium hydroxide transforms into the cadmium oxide phase. The deposited films showed good adherence to the substrate after annealing.

\section{RESULTS AND DISCUSSION}

X-ray diffraction structural analysis: $\mathrm{X}$-ray diffraction patterns of CdO samples were recorded in PANalytical X'Pert Pro XRD with $\mathrm{CuK}_{\alpha}$ radiation $(\mathrm{k}=1.54056 \AA)$ at room temperature. Surface morphology was analyzed by ultrahigh resolution transmission electron microscope (UHRTEM) (JEM 2100) operated at $200 \mathrm{kV}$.
X-ray diffraction pattern of $\mathrm{CdO}$ films calcined at $350{ }^{\circ} \mathrm{C}$ is shown in Fig. 1. The sharp and well defined peaks confirm a face centered cubic (fcc) structure of $\mathrm{CdO}$. The inter-planar spacing (d) [calculated from the Bragg equation (eqn. 2)] and lattice constant (a) (calculated from eqn. 1 for cubic phase structure) of CdO-films samples with different molarities were determined which is very close to the reported values (JCPDS, No. 05-0640).

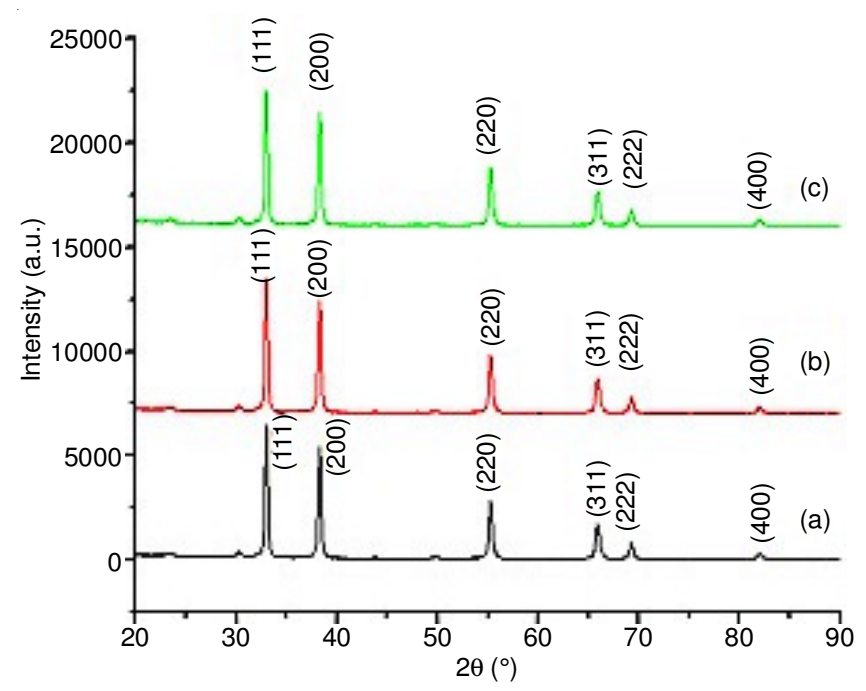

Fig. 1. XRD Patterns of CdO films with molarities (a) $0.25 \mathrm{M}$, (b) $0.50 \mathrm{M}$ and (c) $0.75 \mathrm{M}$

Lattice constant: The lattice constant ' $a$ ' for the cubic phase structure is determined by the relation:

$$
\mathrm{a}=\mathrm{d}\left(\mathrm{h}^{2}+\mathrm{k}^{2}+l^{2}\right)^{1 / 2}
$$

where ' $d$ ' is the interplanar spacing of the crystal planes represented by Miller Indices ( $\mathrm{k} \mathrm{l}$ ) and is given by

$$
\lambda=2 \mathrm{~d} \sin \theta
$$

The corrected values of lattice constants are estimated from the Nelson-Riley plots. The Nelson-Riley curve is a plot between the calculated ' $a$ ' for different planes and error function [20] given by

$$
f(\theta)=\frac{1}{2}\left(\frac{\cos ^{2} \theta}{\sin \theta}+\frac{\cos ^{2} \theta}{\theta}\right)
$$

and extrapolation to $\theta=90^{\circ}$. A typical Nelson-Riley plot for synthesized samples are shown in Fig. 2 and values are shown in Table-1. The lattice constant ' $\mathrm{a}_{\text {corr }}$ ' of the film calculated using Nelson-Riley plot (Table-1) is different from its bulk value $\mathrm{a}_{\mathrm{o}}$ which is $4.696 \AA$. This means the particles are under strain which contributes towards broadening of the diffraction peak. It is clear from the Fig. 1 that all peaks corresponds to fcc structure of $\mathrm{CdO}$ and no other impurity peaks are found.

Crystallite size: Crystallite size of the prepared CdOFilms is estimated from the Scherrer's formula [21]:

$$
\beta_{\mathrm{D}}=\frac{\kappa \lambda}{\mathrm{D} \cos \theta}
$$

where the constant $\mathrm{K}$ is taken as $0.9, \lambda$ is the wavelength of the wavelength of X-rays used $(\lambda=1.5406 \AA), \beta_{\mathrm{D}}$ is the full width at half maximum of the diffraction peaks. 

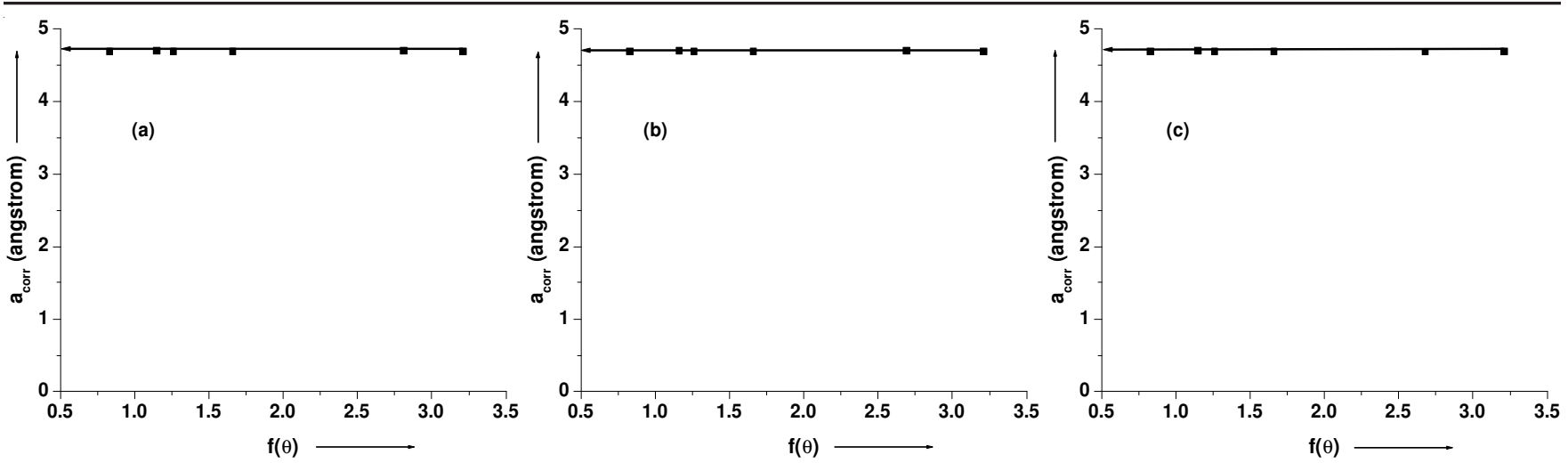

Fig. 2. Nelson-Riley plots of CdO films for (a) $0.25 \mathrm{M}$, (b) $0.50 \mathrm{M}$ and (c) $0.75 \mathrm{M}$

\begin{tabular}{ccccccc}
\multicolumn{8}{c}{ TABLE-1 } \\
$\begin{array}{c}\text { STRUCTURAL PARAMETERS OF CHEMICALLY DEPOSITED } \\
\text { CdO FILMS WITH DIFFERENT MOLARITIES }\end{array}$ \\
\hline $\begin{array}{c}\text { Molarity } \\
(\mathrm{M})\end{array}$ & $\mathrm{d}(\AA)$ & $\mathrm{hkl}$ & $\begin{array}{c}\text { FWHM } \\
\beta\left({ }^{\circ}\right)\end{array}$ & $2 \theta\left(^{\circ}\right)$ & $\begin{array}{c}\mathrm{a}_{\text {calc }} \\
(\AA)\end{array}$ & $\begin{array}{c}\mathrm{a}_{\text {corr }} \\
(\AA)\end{array}$ \\
\hline \multirow{6}{*}{0.25} & 2.711 & 111 & 0.261 & 32.99 & 4.695 & \\
& 2.347 & 200 & 0.288 & 38.29 & 4.700 & \\
& 1.659 & 220 & 0.355 & 55.28 & 4.692 & 4.694 \\
& 1.415 & 311 & 0.406 & 65.92 & 4.693 & \\
& 1.356 & 222 & 0.413 & 69.25 & 4.697 & \\
& 1.173 & 400 & 0.466 & 82.02 & 4.692 & \\
\hline \multirow{6}{*}{0.50} & 2.711 & 111 & 0.227 & 33.03 & 4.695 & \\
& 2.347 & 200 & 0.241 & 38.32 & 4.694 & \\
& 1.659 & 220 & 0.294 & 55.31 & 4.692 & 4.695 \\
& 1.415 & 311 & 0.324 & 65.94 & 4.693 & \\
& 1.356 & 222 & 0.329 & 69.27 & 4.697 & \\
& 1.174 & 400 & 0.379 & 82.03 & 4.698 & \\
\hline \multirow{6}{*}{0.75} & 2.711 & 111 & 0.206 & 33.08 & 4.695 & \\
& 2.340 & 200 & 0.222 & 38.37 & 4.680 & \\
& 1.659 & 220 & 0.270 & 55.36 & 4.692 & 4.694 \\
& 1.415 & 311 & 0.312 & 65.99 & 4.693 & \\
& 1.356 & 222 & 0.317 & 69.32 & 4.697 & \\
& 1.174 & 400 & 0.345 & 82.09 & 4.696 & \\
\hline
\end{tabular}

Williamson-Hall method: In X-ray diffraction, the broadening of XRD line profile is not only due to crystallite size but also due to the presence of non-uniform strain in the material. If the size and strain broadening is present simultaneously then crystallite size and strain may be found from Williamson-Hall plot.

Crystal imperfections and distortion of strain induced peak broadening are related by:

$$
\varepsilon=\frac{\beta_{\mathrm{S}}}{4 \tan \theta} \Rightarrow \beta_{\mathrm{S}}=4 \varepsilon \tan \theta
$$

Depending on different ' $\theta$ ' positions, the separation of size and strain broadening analysis is done using WilliamsonHall method:

$$
\beta=\beta_{\mathrm{S}}+\beta_{\mathrm{D}}
$$

Substituting eqns. 4 and 5 in the above equation we get,

$$
\begin{gathered}
\beta=\frac{\kappa \lambda}{\mathrm{D} \cos \theta}+4 \varepsilon \tan \theta \\
\Rightarrow \beta \cos \theta=\frac{\kappa \lambda}{\mathrm{D}}+4 \varepsilon \sin \theta
\end{gathered}
$$

Eqn. 7 represents the uniform deformation model (UDM). Here the strain is assumed to be uniform in all crystallographic directions. The breadth of Bragg peak is a combination of both instrument and sample dependent effects. To decouple these contributions, it is necessary to collect a diffraction pattern from the line broadening of a standard material such as silicon to determine the instrumental broadening. The instrumental broadening corrected FWHM $(\beta)$ of each reflection is calculated using the following equation [22]

$$
\beta^{2}=(\beta)_{\text {measured }}^{2}-(\beta)_{\text {instrumental }}^{2}
$$

A graph is drawn with $4 \sin \theta$ along $X$-axis and $\beta \cos \theta$ along Y-axis (Fig. 3). From the graph, strain and crystallite size are calculated from the slope and y intercept of the fitted line respectively and the values are tabulated in Table-2. It is observed that there is a gradual increase in crystallite size obtained both from Scherrer's formula and Williamson-Hall plot with the increase in the molarities of the solutions [Fig. 4(a) and 4(b)]. A similar kind of result has been also reported earlier by other workers [23]. There is a decrease in strain with molarity [Fig. 4(c)].
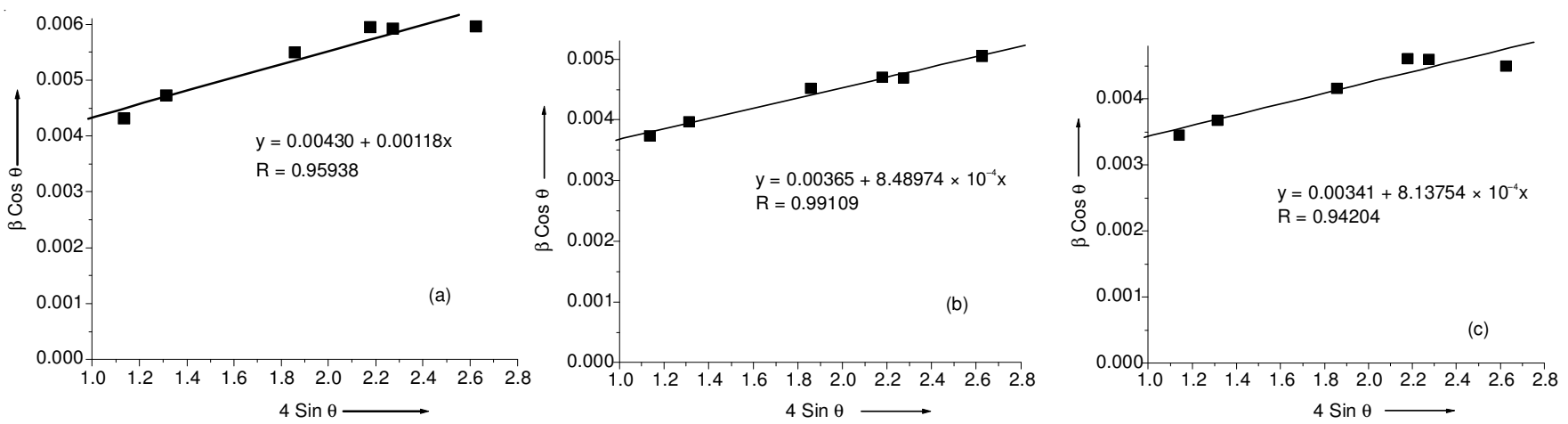

Fig. 3. Williamson-Hall plots of CdO films for (a) $0.25 \mathrm{M}$, (b) $0.50 \mathrm{M}$ and (c) $0.75 \mathrm{M}$ 


\begin{tabular}{|c|c|c|c|c|c|c|c|c|c|c|}
\hline \multirow{4}{*}{$\begin{array}{l}\text { Molarity } \\
\text { of } \\
\text { solution } \\
\text { (M) }\end{array}$} & \multirow{3}{*}{$\begin{array}{c}\text { GEOMET } \\
\begin{array}{c}\text { Scherrer } \\
\text { method }\end{array}\end{array}$} & \multicolumn{8}{|c|}{$\begin{array}{l}\text { TABLE-2 } \\
\text { FILMS US }\end{array}$} & \\
\hline & & \multicolumn{9}{|c|}{ Williamson method } \\
\hline & & \multicolumn{2}{|c|}{ UDM } & \multicolumn{3}{|c|}{ USDM } & \multicolumn{4}{|c|}{ UDEDM } \\
\hline & $\mathrm{D}(\mathrm{nm})$ & $\mathrm{D}(\mathrm{nm})$ & $\begin{array}{c}\text { Strain } \\
\varepsilon \times 10^{-3}\end{array}$ & $\mathrm{D}(\mathrm{nm})$ & $\begin{array}{c}\text { Strain } \\
\varepsilon \times 10^{-3}\end{array}$ & $\begin{array}{c}\text { Stress } \\
\sigma(\mathrm{MPa}) \\
\end{array}$ & $\mathrm{D}(\mathrm{nm})$ & $\begin{array}{l}\text { Strain } \\
\varepsilon \times 10^{-3}\end{array}$ & $\begin{array}{c}\text { Stress } \\
\sigma(\mathrm{MPa}) \\
\end{array}$ & $\mathrm{u}\left(\mathrm{KJ} / \mathrm{m}^{3}\right)$ \\
\hline 0.25 & 30.02 & 33.66 & 1.180 & 34.55 & 1.087 & 158.34 & 34.55 & 1.136 & 165.58 & 94.09 \\
\hline 0.50 & 35.49 & 39.66 & 0.849 & 40.32 & 0.933 & 136.02 & 40.89 & 0.822 & 119.76 & 49.28 \\
\hline 0.75 & 38.78 & 42.45 & 0.814 & 43.60 & 0.741 & 108.01 & 42.45 & 0.779 & 113.50 & 44.22 \\
\hline
\end{tabular}
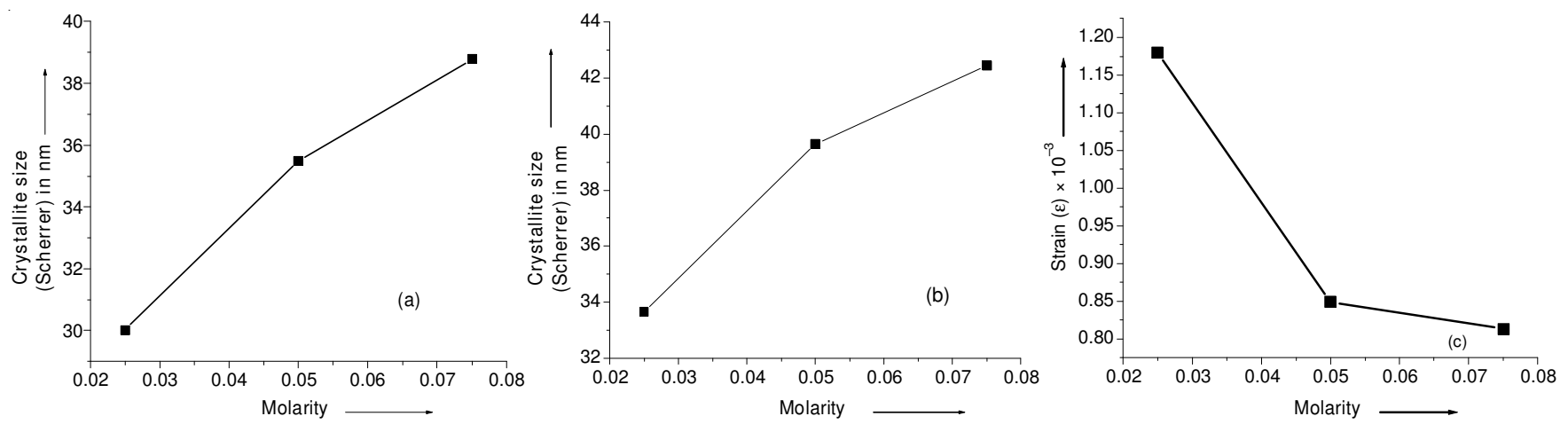

Fig. 4. (a) Crystallite size from Scherrer's formula versus molarity. (b) Crystallite size from Williamson-Hall plot versus molarity. (c) Strain from Williamson-Hall plot versus molarity of $\mathrm{CdO}$

Size-strain plot method: Size-strain plot' (SSP) can be used for estimation of size-strain parameters for isotropic line broadening. In this method, less importance is given to the data from reflection at high angles, because, normally precision is less in those ranges of angles [24]. In this approximation method, the "crystallite size" profile is described by a Lorentzian function and the "strain profile" is described by Gaussian function [25]. Then one can write:

$$
\left(\frac{\mathrm{d} \beta \cos \theta}{\lambda}\right)^{2}=\frac{1}{\mathrm{D}}\left(\frac{\mathrm{d}^{2} \beta \cos \theta}{\lambda}\right)+\left(\frac{\varepsilon}{2}\right)^{2}
$$

The term $\left(\frac{\mathrm{d}^{2} \beta \cos \theta}{\lambda}\right)$ is plotted along $\mathrm{X}$-axis against $\left(\frac{\mathrm{d} \beta \cos \theta}{\lambda}\right)^{2}$ along Y-axis for different peak orientations of 0.25, 0.50 and $0.75 \mathrm{M}$ of $\mathrm{CdO}$ films as shown in Fig. 5(a)5(c). The crystallite size is determined from the slope of the linearly fitted data and the value of strain is obtained from $y$-intercept. The size of the crystallite is obtained from $\mathrm{D}=\frac{\mathrm{k} \lambda}{\text { slope }}$ where $\mathrm{K}=3 / 4$ for spherical particle. The mean
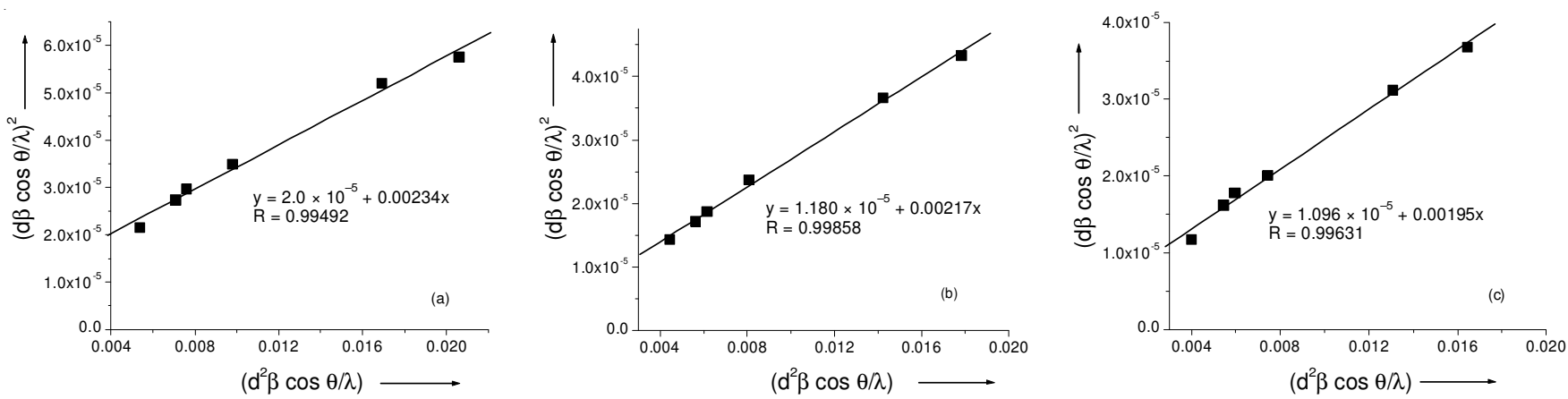

Fig. 5. Size-strain plots of CdO films for (a) $0.25 \mathrm{M}$, (b) $0.50 \mathrm{M}$ and (c) $0.75 \mathrm{M}$ apparent strain is $\varepsilon_{\text {app }}=2(\sqrt{\mathrm{y} \text { intercept }})$ and the root mean square strain is obtained from relation [26] $\varepsilon=\frac{\varepsilon_{\text {app }}}{2 \pi \sqrt{2}}$. The estimated values of $D$ and $\varepsilon$ are shown in Table-3.

\section{TABLE-3}

GEOMETRIC PARAMETERS OF CdO FILMS PREPARED USING SIZE-STRAIN PLOT METHOD

\begin{tabular}{ccc}
\hline Molarity of solution $(\mathrm{M})$ & $\mathrm{D}(\mathrm{nm})$ & Strain $\varepsilon \times 10^{-3}$ \\
\hline 0.25 & 49.36 & 1.009 \\
0.50 & 53.22 & 0.766 \\
0.75 & 59.23 & 0.751 \\
\hline
\end{tabular}

Modified Williamson-Hall method: From uniform stress deformation model (USDM), strain is calculated from Hooke's law maintaining linear proportionality between stress and strain given by $\sigma=\mathrm{Y} \varepsilon$ where $\sigma$ is the stress, $\varepsilon$ is the strain and $\mathrm{Y}$ is the Young's modulus. Applying Hooke's law approximation to eqn. 7 , we get:

$$
\beta \cos \theta=\frac{\kappa \lambda}{\mathrm{D}}+\frac{4 \sigma}{\mathrm{Y}} \sin \theta
$$


Again, the modulus of elasticity or Young's modulus ' $\mathrm{Y}$ ' for cubic crystal is given by the relation [27]:

$$
\frac{1}{\mathrm{Y}}=\mathrm{S}_{11}-2\left(\mathrm{~S}_{11}-\mathrm{S}_{12}-\frac{1}{2} \mathrm{~S}_{44}\right) \frac{(\mathrm{hk})^{2}+(\mathrm{hl})^{2}+(\mathrm{kl})^{2}}{\left(\mathrm{~h}^{2}+\mathrm{k}^{2}+\mathrm{l}^{2}\right)^{2}}
$$

where $\mathrm{S}_{11}, \mathrm{~S}_{12}, \mathrm{~S}_{44}$ are the elastic compliances of $\mathrm{CdO}$. The relation connecting elastic compliances and the stiffness $C_{i j}$ are as follows [28]:

$$
\begin{gathered}
S_{11}=\frac{C_{11}+C_{12}}{\left(C_{11}-C_{12}\right)\left(C_{11}+2 C_{12}\right)} \\
S_{12}=-\frac{C_{12}}{\left(C_{11}-C_{12}\right)\left(C_{11}+2 C_{12}\right)}
\end{gathered}
$$

and

$$
\mathrm{S}_{44}=\frac{1}{\mathrm{C}_{44}}
$$

Using the values of $\mathrm{C}_{11}, \mathrm{C}_{12}$ and $\mathrm{C}_{44}$ [29] as $207.8 \mathrm{GPa}$, 106.3 GPa and 54.9 GPa respectively, we can calculate elastic compliances $\mathrm{S}_{11}, \mathrm{~S}_{12}, \mathrm{~S}_{44}$ which are given as $7.36 \times 10^{-12},-2.49$ $\times 10^{-12}$ and $18.21 \times 10^{-12} \mathrm{~m}^{2} / \mathrm{N}$ respectively. Young's modulus $\mathrm{Y}$ has been calculated and resulted to be $145.7 \mathrm{GPa}$ for (111) lattice plane followed by $\mathrm{Y}=135.9 \mathrm{GPa}$ for (200), $\mathrm{Y}=143.1$ $\mathrm{GPa}$ for (220), $\mathrm{Y}=140.3 \mathrm{GPa}$ for (311), $\mathrm{Y}=145.69 \mathrm{GPa}$ for (222) and $\mathrm{Y}=135.9 \mathrm{GPa}$ for (400) lattice planes, respectively. A graph is plotted between $4 \sin \theta / Y$ along $X$-axis and $\beta \cos \theta$ along Y-axis (Fig. 6). The stress is calculated from the slope of the graph and crystallite size from the $\mathrm{Y}$ intercept and the values are presented in Table-2. The energy density of a crystal was calculated from a model called uniform deformation energy density model (UDEDM). According to Hooke's law, the energy density $u$ (energy per unit volume) is $u=\frac{\varepsilon^{2} Y}{2}$.

Therefore, eqn. 7 can be modified to the form:

$$
\beta \cos \theta=\frac{\kappa \lambda}{\mathrm{D}}+4 \sin \theta\left(\frac{2 \mathrm{u}}{\mathrm{Y}}\right)^{1 / 2}
$$

A graph is plotted between $4 \sin \theta\left(\frac{2}{Y}\right)^{1 / 2}$ along $X$-axis and $\beta \cos \theta$ along Y-axis (Fig. 7). From the slope of the graph, energy density $\mathrm{u}$ is calculated and the crystallite size $\mathrm{D}$ is calculated from the $\mathrm{Y}$ intercept and the values are tabulated in Table-2.

Transmission electron microscopy: The UHRTEM micrograph of CdO sample of 0.50 molarity is shown in Fig. 8(a). The image of $\mathrm{CdO}$ sample shows the presence of large number of nearly spherical $\mathrm{CdO}$ nanoparticles. The shapes of the particles are nearly spherical and obviously demonstrate aggregation of the particles. The aggregation of particles should had been originated from the large specific surface area and high surface energy of $\mathrm{CdO}$ nanoparticles [30]. The aggregation occurred probably during the process of drying [31,32]. The average particle size of the $\mathrm{CdO}$ sample is found to be 50 $\mathrm{nm}$, which is very nearly close to the result obtained based on XRD study $(53.22 \mathrm{~nm})$ by SSP method. Fig. 8(b) shows selected area electron diffraction (SAED) pattern of the sample consisting of a central halo and concentric rings, which indicate the crystalline structure of the sample. The well crystallinity can be observed in lattice planes along (111), (200) and (220) having values of $\mathrm{d}(\mathrm{nm})$ (interplanar spacing of the crystal planes) as $0.275,0.235$ and 0.166 respectively [Fig. 8(b)] and the selected area diffraction pattern (SAED) is shown in inset [Fig. 8(c)].
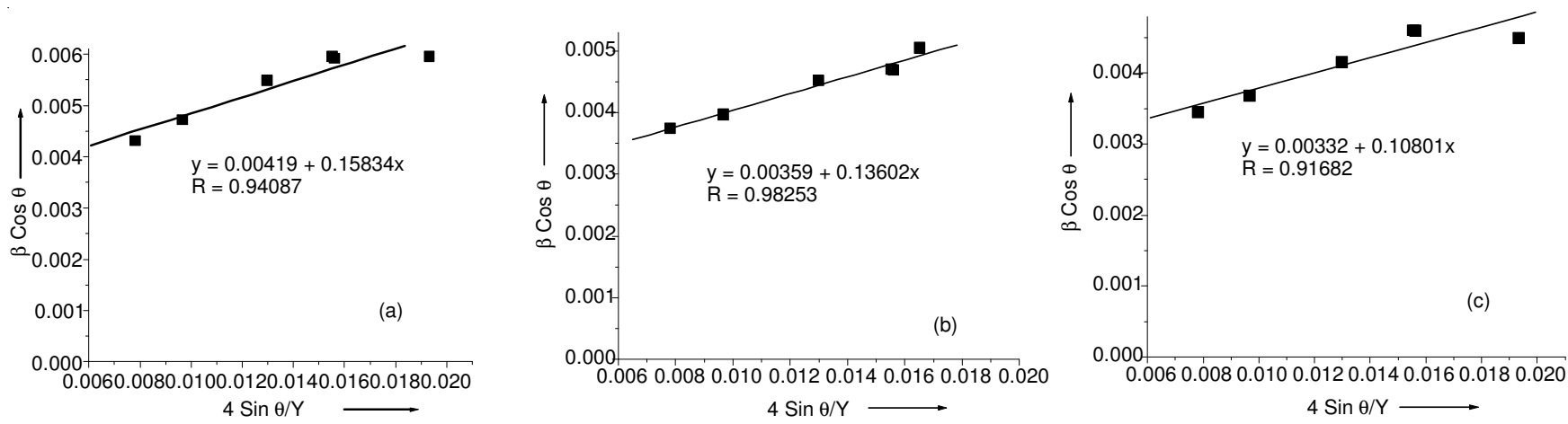

Fig. 6. Modified Williamson-Hall plots of CdO films for (a) $0.25 \mathrm{M}$, (b) $0.50 \mathrm{M}$ and (c) $0.75 \mathrm{M}$
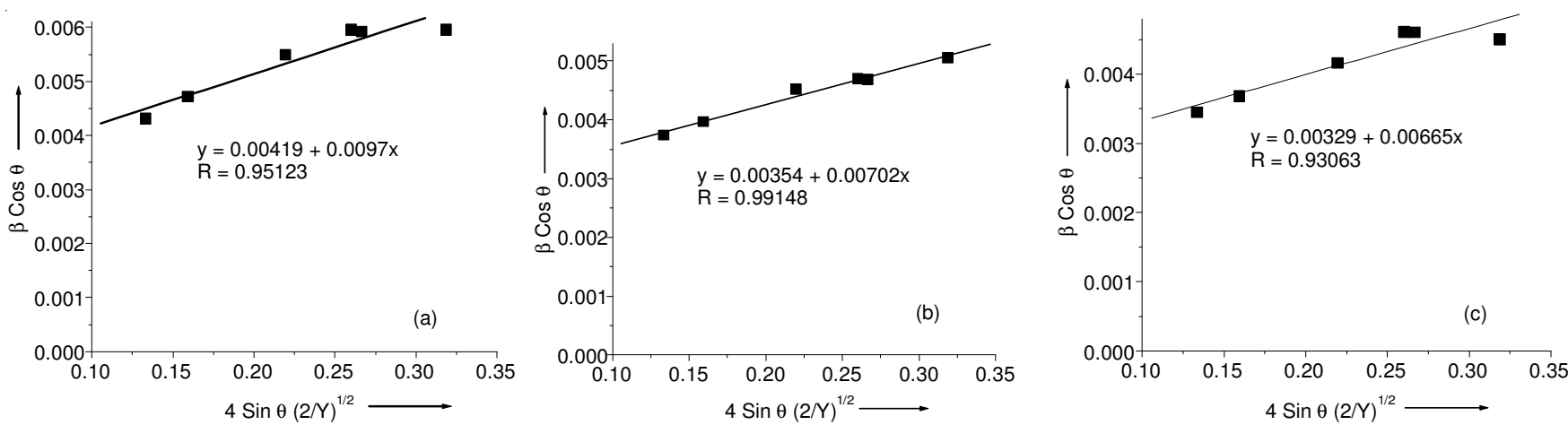

Fig. 7. Uniform deformation energy density model plot of CdO films for (a) $0.25 \mathrm{M}$, (b) $0.50 \mathrm{M}$ and (c) $0.75 \mathrm{M}$ 


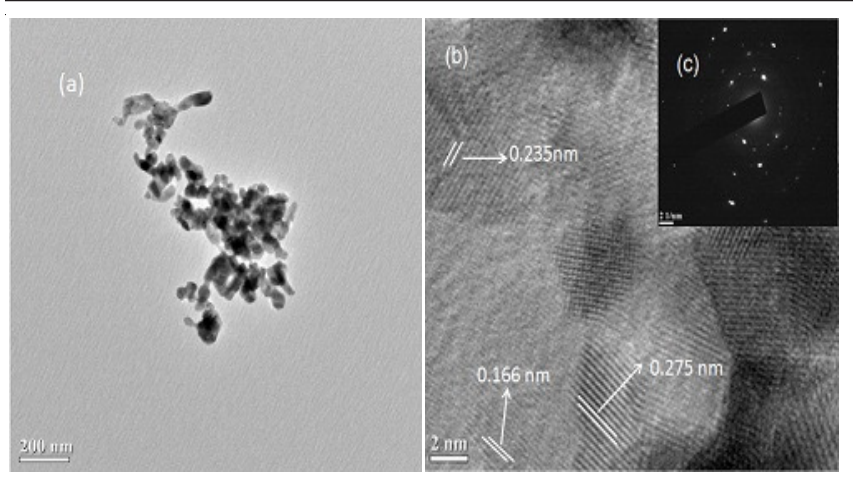

Fig. 8. (a) TEM micrograph of $\mathrm{CdO}$ sample with $0.50 \mathrm{M}$ (b) lattice planes and (c) SAED pattern of CdO of molarity $0.50 \mathrm{M}$ (inset)

\section{Conclusion}

Nanostructured CdO films deposited by SILAR method are found to be uniform and have good adherence to the substrates. The formation of $\mathrm{CdO}$ nanoparticles have been confirmed by XRD and HRTEM analyses. The peak broadening was analyzed by the Scherrer's equation, SSP and modified forms of Williamson-Hall models viz. UDM, USDM and UDEDM. Among Williamson-Hall methods, UDM considers the homogeneous isotropic nature of the crystal where as USDM and UDEDM models consider the anisotropic nature of the crystallites. The average values of crystallite size obtained from UDM, USDM and UDEDM are almost similar which indicate the inclusion of strain in various forms of WilliamsonHall analysis has some effect on the average crystallite size of $\mathrm{CdO}$ nanoparticles. Some variation in the average crystallite size obtained from Scherrer's formula and Williamson-Hall analysis was due to the difference in averaging the particle size distribution. The above-explained methods were helpful in determining the crystallite size, strain, stress and energy density value and among them SSP method is highly preferable to define the crystal perfection. From different models and methods, it is seen that with the increase in molar concentration of the precursor solutions strain, stress and energy density of the nanocrystals decrease, whereas crystallite size of the prepared $\mathrm{CdO}$ films increases.

\section{ACKNOWLEDGEMENTS}

The authors would like to thank SAIF, Gauhati University, Guwahati, India for XRD analysis and also thankful to SAIF, NEHU, Shillong, India for TEM analysis.

\section{REFERENCES}

1. V.S. Muralidharan and A. Subramania, Nanoscience and Technology, CRC Press, New Delhi, pp. 542 (2009).

2. B.C. Ejelonu and P.A. Ajibade, Chalcogenide Lett., 13, 563 (2016).

3. D.R. Lide, CRC Handbook of Chemistry and Physics, CRC Press, Boca Raton, edn 77, p. 12/97 and 3/278 (1996/97).

4. F. Zhang, F. Bei, J. Cao and X. Wang, J. Solid State Chem., 181, 143 (2008);

https://doi.org/10.1016/j.jssc.2007.11.004.

5. N.C.S. Selvam, R.T. Kumar, K. Yogeenth, L.J. Kennedy, G. Sekaran and J.J. Vijaya, Powder Technol., 211, 250 (2011); https://doi.org/10.1016/j.powtec.2011.04.031.
6. N. Varghese, L.S. Panchakarla, M. Hanapi, A. Govindaraj and C.N.R. Rao, Mater. Res. Bull., 42, 2117 (2007); https://doi.org/10.1016/j.materresbull.2007.01.017.

7. D.D. Vijaykarthik, M. Kirithika, N. Prithivikumaran and N. Jeyakumaran, Int. J. Nano Dimens., 5, 557 (2014); https://doi.org/10.7508/ijnd.2014.06.007.

8. T. Kuo and M.H. Huang, J. Phys. Chem. B, 110, 13717 (2006); https://doi.org/10.1021/ip062854x.

9. H.B. Lu, L. Liao, H. Li, Y. Tian, D.F. Wang, J.C. Li, Q. Fu, B.P. Zhu and Y. Wu, Mater. Lett., 62, 3928 (2008); https://doi.org/10.1016/j.matlet.2008.05.010.

10. A. Askarinejad and A. Morsali, Mater. Lett., 62, 478 (2008); https://doi.org/10.1016/j.matlet.2007.05.082.

11. A. Tadjarodi and M. Imani, Mater. Lett., 65, 1025 (2011); https://doi.org/10.1016/j.matlet.2010.12.054.

12. A. Ivanauskas, R. Ivanauskas and I. Ancutiene, Chalcogenide Lett., 13, 373 (2016)

13. N. Choudhury and B.K. Sarma, Bull. Mater. Sci., 32, 43 (2009); https://doi.org/10.1007/s12034-009-0007-y.

14. P.K. Mochahari and K.C. Sarma, Indian J. Phys., 88, 1265 (2014); https://doi.org/10.1007/s12648-014-0590-7.

15. V.D. Mote, Y. Purushotham and B.N. Dole, J. Theor. Appl. Phys., 6, 6 (2012); doi:10.1186/2251-7235-6-6

16. Y.T. Prabhu, K.V. Rao, V.S. Kumar and B.S. Kumari, World J. Nano Sci. Eng., 4, 21 (2014); https://doi.org/10.4236/wjnse.2014.41004

17. P. Triloki, P. Garg, R. Rai and B.K. Singh, Nucl. Instrum. Methods Phys. Res. A, 736, 128 (2014); https://doi.org/10.1016/i.nima.2013.10.075.

18. P.K. Mochahari, A. Rajbongshi, N. Choudhury, F. Singh and K.C. Sarma, Adv. Mater. Lett., 6, 354 (2015); https://doi.org/10.5185/amlett.2015.5719.

19. P.K. Mochahari and K.C. Sarma, Indian J. Phys., 90, 21 (2016); https://doi.org/10.1007/s12648-015-0721-9.

20. J.B. Nelson and D.P. Riley, Proc. Phys. Soc. Lond., 57, 160 (1945); https://doi.org/10.1088/0959-5309/57/3/302.

21. S. Sen, S. K. Halder and S. P. Sen Gupta, J. Phys. Soc. Jpn., 38, 1641 (1975); https://doi.org/10.1143/JPSJ.38.1641.

22. K.D. Rogers and P. Daniels, Biomaterials, 23, 2577 (2002); https://doi.org/10.1016/S0142-9612(01)00395-7.

23. V. Saravanan, J. Joseph Prince and M. Anusuya, APRN J. Eng. Appl. Sci., 10, 2453 (2015).

24. A.K. Zak and W.H.A. Majid, Ceram. Int., 36, 1905 (2010); https://doi.org/10.1016/j.ceramint.2010.03.022.

25. M.A. Tagliente and M. Massaro, Nucl. Instrum. Methods Phys. Res. B, 266, 1055 (2008); https://doi.org/10.1016/j.nimb.2008.02.036.

26. P. Rageswari and S. Dhanuskodi, Cryst. Res. Technol., 48, 589 (2013); https://doi.org/10.1002/crat.201300102.

27. J.-M. Zhang, Y. Zhang, K.-W. Xu and V. Ji, Mater. Lett., 62, 1328 (2008); https://doi.org/10.1016/j.matlet.2007.08.038.

28. A.A. Kelly and K.M. Knowles, Crystallography and Crystal Defects, Wiley, edn 2 (2012).

29. A.J. Cinthia, G. Sudhapriyang, R. Rajeswarapalanichamy and M. Santhosh, Procedia Mater. Sci., 5, 1034 (2014); https://doi.org/10.1016/j.mspro.2014.07.394.

30. D. Raoufi, J. Lumin., 134, 213 (2013); https://doi.org/10.1016/j.jlumin.2012.08.045.

31. R.Y. Hong, J.Z. Qian and J.X. Cao, Powder Technol., 163, 160 (2006); https://doi.org/10.1016/j.powtec.2006.01.015.

32. R.Y. Hong, J.H. Li, L.L. Chen, D.Q. Liu, H.Z. Li, Y. Zheng and J. Ding, Powder Technol., 189, 426 (2009); https://doi.org/10.1016/j.powtec.2008.07.004. 